\title{
Predictors of ceasing or reducing statin medication following a large increase in the consumer copayment for medications: a retrospective observational study
}

\section{Karla Seamana,b,i, Frank Sanfilippoc, Max Bulsara ${ }^{d}$, Libby Rougheade, Anna Kemp-Casey ${ }^{\dagger}$, Caroline Bulsaraa, Gerald F Watts ${ }^{g, h}$ and David Preen ${ }^{\dagger}$}

a School of Health Sciences, University of Notre Dame, Perth, WA, Australia

b School of Nursing and Midwifery, Edith Cowan University, Perth, WA, Australia

c Cardiovascular Research Group, School of Population and Global Health, University of Western Australia, Perth

d Institute for Health Research, University of Notre Dame, Perth, WA, Australia

e Sansom Institute for Health Research, School of Pharmacy and Medical Sciences, University of South Australia, Adelaide

${ }^{f}$ Centre for Health Services Research, School of Population and Global Health, University of Western Australia, Perth

g Lipid Disorders Clinic, Department of Cardiology, Royal Perth Hospital, WA, Australia

n School of Medicine and Pharmacology, University of Western Australia, Perth

i Corresponding author: karla.seaman1@my.nd.edu.au

\section{Article history}

\section{Publication date: March 2020}

Citation: Seaman K, Sanfilippo F, Bulsara M,

Roughead L, Kemp-Casey A, Bulsara C, Watts GF,

Preen D. Predictors of ceasing or reducing statin medication following a large increase in the consumer copayment for medications: a retrospective observational study. Public Health Res Pract. 2020;30(1):e29121905. First published: 2 May 2019. https://doi.org/10.17061/ phrp29121905

\section{Key points}

- The proportion of individuals who reduced or ceased use of statin medications in 2005 increased by $2.1 \%$ compared with 2004, following an increase in the Pharmaceutical Benefits Scheme copayment for medications

- Of those who ceased or reduced statin use, $8 \%$ and $10 \%$, respectively, had prior heart disease, putting them at an increased risk of harms from suboptimal use of lipid-lowering therapy

- General beneficiary status, and younger and healthier people were particularly at risk of ceasing or reducing statin medication

- The findings provide policy makers and clinicians with new information about the impact of a large increase in the medication copayment on the use of medications by specific subgroups

\section{Abstract}

Objectives: Previous Australian research has shown that following the $21 \%$ increase in patient copayments for medications on the Pharmaceutical Benefits Scheme (PBS) in 2005, the use of lipidlowering therapy declined by $5 \%$. This study aimed to determine the demographic and clinical characteristics of individuals who continued, reduced or ceased their use of statin medication in 2005.

Study type: Retrospective observational study using routinely collected administrative data.

Method: We used pharmaceutical claims, hospital separations and mortality records from 2000 to 2005 for the Western Australian population. The cohort comprised stable users of statin medication in 2004. Based on changes in statin use between 2004 and 2005, we identified individuals who: 1) continued using statins; 2) reduced their use by $\geq 20 \%$; or 3 ) ceased therapy for at least the first 6 months in 2005. Multivariate logistic regression models were used to determine whether the demographic and clinical characteristics of the three groups differed.

Results: There were 205924 statin users identified in Western Australia as of December 2004. After the January 2005 Pharmaceutical Benefits Scheme (PBS) copayment increase, 3.2\% of users ceased their regular statin therapy, $12.9 \%$ reduced statin use and $83.9 \%$ continued statin use. This represented a $2.1 \%$ increase in statin users reducing or ceasing therapy compared to 2004. Predictors of cessation and reduction of statin therapy included 
younger age, greater socio-economic disadvantage, residing in very remote areas, having general beneficiary status, being a new statin user, having no prior history of ischaemic heart disease, having no prior history of a coronary artery revascularisation procedure, taking no other cardiovascular medication or diabetic medication, taking an increased number of medications, and having a lower level of adherence to statin medication in 2004.

Conclusion: Compared to 2004, an additional 2.1\% of statin users reduced or discontinued medication use in 2005 , which may be attributed to an increase in the medication copayment. Individuals with general beneficiary status, and younger and healthier people were at particular risk of cessation or reduction in statin use in 2005.

\section{Introduction}

Feasible solutions are needed to contain rising healthcare costs, including those of medications, in private and public healthcare services. ${ }^{1}$ Many subsidised medication programs, such as the Pharmaceutical Benefits Scheme (PBS) in Australia, have adopted a consumer copayment scheme to offset health costs. Consumer copayments were introduced by the Australian Government via the PBS in 1960, and are one of many policies adopted to manage rising healthcare costs. Under the PBS, consumers pay an out-of-pocket cost (copayment) for their medications. The copayment depends on the consumer's beneficiary status (general or concessional), which is largely based on the individual's ability to pay. ${ }^{2}$

PBS copayments increase annually, generally in line with inflation. ${ }^{2}$ However, on 1 January 2005, a 21\% copayment increase occurred for both general patients (from AU\$23.70 to AU\$28.60 per item dispensed) and concessional patients (AU\$3.80 to AU\$4.60).

Large increases in the PBS copayment are of concern from an individual and population health perspective. National and international evidence suggests that rising medication costs can result in consumers ceasing or reducing their medication use..$^{3-5}$

Previous research using aggregated data has demonstrated that, following the PBS copayment increase in January 2005, the volume of medication dispensed in Australia decreased significantly (from 3\% to 11\% for 12 of the 17 medication categories examined). ${ }^{3}$ The largest reductions were observed for concessional (lower-income) individuals. Essential medications used to manage serious but asymptomatic conditions, such as lipid-lowering therapy, were among the most affected at a population level, with dispensing decreasing by $5 \% .{ }^{6}$ Although a $5 \%$ change is small in relative terms, it is large in absolute terms in this particular instance and has serious potential for harm. An Australian study demonstrated that statin dispensing in Australia fell by $2.6 \%$ following a 2013 television program that was critical of statin therapy, and estimated that this resulted in between 1522 and 2900 preventable heart attacks and strokes. ${ }^{7}$
Previous studies investigating the impact of the 2005 PBS copayment increase have been restricted to using aggregate data with limited information on individual patient characteristics, or small self-reported samples. The effects of the 2005 copayment increase need to be explored further using individual-level data. To date, the Austalian Government has not introduced another copayment increase of this magnitude. We aimed to determine the demographic and clinical characteristics of individuals who ceased or reduced statin medication use after the January 2005 PBS copayment increase in Australia, compared with individuals who continued statin use.

\section{Methods}

\section{Study design}

This retrospective observational study used wholeof-population linked pharmaceutical claims, hospital inpatient and mortality register records for 2000-2005 in Western Australia (WA).

Approval was obtained from the Human Research Ethics Committees of the WA Department of Health (2012/26), the University of Western Australia (RA/4/1/1775) and the University of Notre Dame (014167F).

\section{Study cohort}

The cohort was defined as all individuals residing in WA who were stable statin users as of December 2004. A stable statin user was defined as an individual who had at least 60 days supply of statin medication in the last 3 months or 150 days supply in the last 6 months of 2004 . Individuals were excluded if they were aged $<18$ years in 2004, died before January 2006 or had a medication possession ratio (MPR) in 2004 of $>150 \%$. The $150 \%$ cut-off was chosen because Australian regulations allow up to 6 months supply of a medication at once in special circumstances, and to account for standard end-of-year fluctuations in dispensing frequency due to the PBS Safety Net. 8,9 
Statins were identified in the PBS dataset using the Anatomical Therapeutic Chemical (ATC) codes C10AA01, C10AA03, C10AA04, C10AA05, C10AA06 and C10AA07.

\section{Data sources and linkages}

This study used de-identified linked data provided by the Australian Government Department of Human Services and the WA Department of Health. Linkage of three independent datasets occurred at the individual patient level through the WA Data Linkage System, as described elsewhere..$^{10}$ The three datasets were: 1) pharmaceutical claims comprising all PBS-subsidised medications from May 2002 to December 2005; 2) WA Mortality Register data for 2000-2005 that included all deaths in WA; and 3) WA Hospital Morbidity Data Collection (HMDC) records for 2000-2004 that included all discharges from WA public and private hospitals.

\section{Comparison groups}

The primary outcome was the change in the level of statin use in 2005, categorised as either continued, reduced or ceased use. Statin adherence levels were calculated for 2004 and 2005 separately using the MPR, which is a proxy measure of medication use. The proportion of days covered could not be calculated as only month of supply, and not actual supply date, was available in the PBS dataset. MPR was computed as the portion of days covered by dispensing from the first day of the month of the first dispensing in the year until the end of the year. Individuals who continued statin therapy were defined as those with a change in MPR from 2004 to 2005 of $\leq 20 \%$ or an MPR of $\geq 80 \%$ in 2005. Reduction in therapy was defined as an MPR change of $>20 \%$, and individuals were classified as ceased users if there was no dispensing in 2005 or no dispensing for the first 6 months of 2005. The $80 \%$ threshold of adherence was based on previous studies on adherence for statin medication. ${ }^{11}$

\section{Demographic and clinical characteristics}

PBS data from the last dispensing in 2004 were used to determine baseline age, sex, area-based social disadvantage, residential remoteness, PBS beneficiary status including Department of Veterans' Affairs healthcare card eligibility, number of other medications dispensed, and prior use of cardiovascular or diabetes medication. Area-based social disadvantage was classified using the Index of Relative Socio-Economic Disadvantage which is based on postal area. ${ }^{12}$ This variable was then divided into quintiles. Level of residential remoteness (as a proxy for access to healthcare services) was assessed using the Accessibility Remoteness Index of Australia and divided into five categories. ${ }^{13}$

Individuals were classified as a new statin user if PBS data showed no dispensing of a statin medication in 2002 or 2003; otherwise they were classified as an 'existing user'. Prior use of cardiovascular or diabetes medication was defined as a dispensing during 2004 of any therapy with ATC codes C01-C10 (except C10AA) or A10, respectively. ${ }^{14,15}$ The number of other medications was based on the number of unique PBS codes dispensed in 2004.

Hospital separations for 2000-2004 were used to determine whether individuals were using statins for primary or secondary prevention of ischaemic heart disease (IHD) or stroke, and whether they had had a prior coronary artery revascularisation procedure (CARP). This information was identified from all diagnosis fields for IHD and stroke, and all producer fields for CARP in the HMDC data, using the ICD-10-AM (International Statistical Classification of Diseases and Related Health Problems, 10th revision, with Australian modifications) codes I20-125 for IHD, and I60-161, I63 and I64 for stroke. ${ }^{16,17}$

\section{Statistical analysis}

Descriptive statistics were used to compare the type of statin user, dichotomised (yes/no) as a user who has continued, reduced or ceased therapy. Crude differences in characteristics among the three user groups (ceased versus continued; reduced versus continued) were initially compared using one-way ANOVA for continuous variables and chi-squared tests for categorical variables. Univariate and multivariate logistic regression models were applied to ceased versus continued (the reference group) and reduced versus continued (the reference group). Unadjusted and adjusted odds ratios (OR) and 95\% confidence intervals $(\mathrm{Cl})$ were calculated for each characteristic. All analysis was stratified by beneficiary status. The study was replicated using 2003-2004 data to determine the proportion of the population that may have ceased or reduced medicine use as a result of the copayment. Bonferroni corrections were applied to all statistical analyses to account for multiple testing. All analyses were conducted using Stata Statistical Software (College Station, TX: StataCorp LLC; Release 15).

\section{Results}

\section{Cohort characteristics}

There were 205924 stable statin users in WA as of December 2004. Of these, $83.9 \%$ continued statin medication in $2005,12.9 \%$ had a reduction in use of $>20 \%$, and $3.2 \%$ ceased statin use for at least the first 6 months of 2005. The three groups had baseline differences across the examined predictors (Table 1). Compared with individuals who continued statin use, those who ceased or reduced their use of statins in 2005 were younger, had less medical history of IHD, stroke and CARP, and were more likely to have general beneficiary status. 
Table 1. Demographic and clinical characteristics of individuals who continued, reduced or ceased statin medication in 2005 ( $n=205924)$, and adjusted odds ratios for reduction or cessation of statin therapy compared with continued therapy

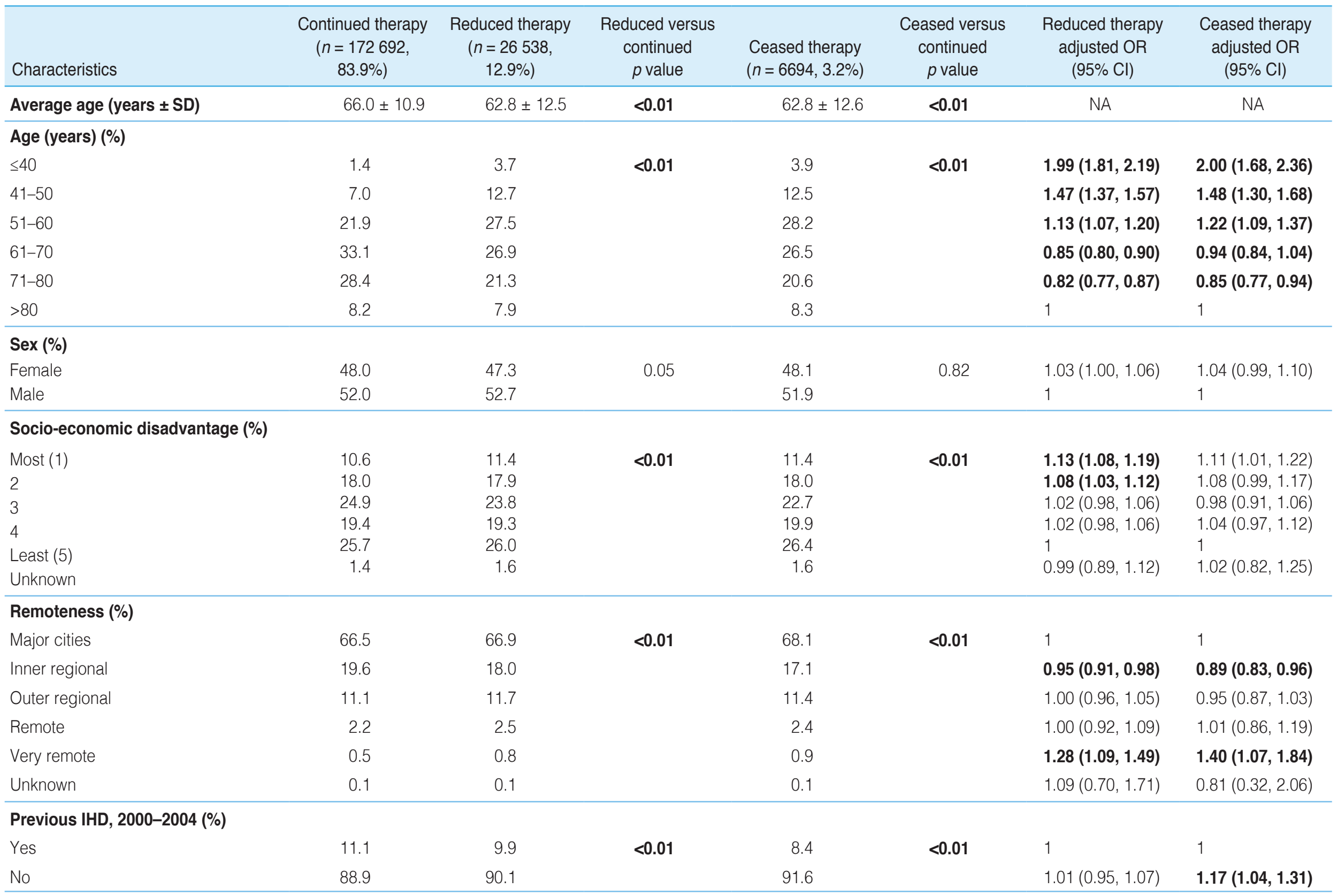


Table 1. continued

\begin{tabular}{|c|c|c|c|c|c|c|c|}
\hline Characteristics & $\begin{array}{l}\text { Continued therapy } \\
\qquad \begin{array}{c}(n=172692, \\
83.9 \%)\end{array}\end{array}$ & $\begin{array}{l}\text { Reduced therapy } \\
\qquad \begin{array}{c}n=26538 \\
12.9 \%)\end{array}\end{array}$ & $\begin{array}{l}\text { Reduced versus } \\
\text { continued } \\
p \text { value }\end{array}$ & $\begin{array}{l}\text { Ceased therapy } \\
(n=6694,3.2 \%)\end{array}$ & $\begin{array}{l}\text { Ceased versus } \\
\text { continued } \\
p \text { value }\end{array}$ & $\begin{array}{l}\text { Reduced therapy } \\
\text { adjusted OR } \\
(95 \% \mathrm{Cl})\end{array}$ & $\begin{array}{c}\text { Ceased therapy } \\
\text { adjusted OR } \\
(95 \% \mathrm{Cl})\end{array}$ \\
\hline
\end{tabular}

Previous stroke, 2000-2004 (\%)

\begin{tabular}{lrrrrrr} 
Yes & 1.3 & 1.2 & 0.14 & 1.1 & 1 & 0.26 \\
No & 98.7 & 98.8 & 98.9 & $1.04(0.92,1.17)$ & $1.16(0.92,1.47)$ \\
\hline
\end{tabular}

Previous CARP, 2000-2004 (\%)

\begin{tabular}{|c|c|c|c|c|c|c|c|}
\hline Yes & 5.1 & 4.5 & $<0.01$ & 3.3 & $<0.01$ & 1 & 1 \\
\hline No & 94.9 & 95.5 & & 96.7 & & $1.08(0.99,1.17)$ & $1.39(1.17,1.65)$ \\
\hline
\end{tabular}

\section{Previous statin use, 2002 and 2003 (\%)}

\begin{tabular}{|c|c|c|c|c|c|c|c|}
\hline Yes & 90.7 & 79.5 & $<0.01$ & 74.4 & $<0.01$ & 1 & 1 \\
\hline No & 9.3 & 20.5 & & 25.6 & & $2.33(2.25,2.42)$ & $3.30(3.11,3.51)$ \\
\hline \multicolumn{8}{|c|}{ Beneficiary status (\%) } \\
\hline General & 26.1 & 35.4 & $<0.01$ & 36.1 & $<0.01$ & $1.17(1.12,1.21)$ & $1.41(1.32,1.52)$ \\
\hline Concessional & 73.9 & 64.6 & & 63.9 & & 1 & 1 \\
\hline
\end{tabular}

\section{Cardiovascular medication, 2004 (\%)}

\begin{tabular}{|c|c|c|c|c|c|c|c|}
\hline Yes & 73.0 & 63.4 & $<0.01$ & 64.5 & $<0.01$ & 1 & 1 \\
\hline No & 27.0 & 36.6 & & 35.5 & & $1.32(1.27,1.36)$ & $1.29(1.22,1.37)$ \\
\hline
\end{tabular}

\section{Diabetic medication, 2004 (\%)}

\begin{tabular}{|c|c|c|c|c|c|c|c|}
\hline Yes & 16.2 & 14.6 & $<0.01$ & 16.2 & 0.97 & 1 & 1 \\
\hline No & 83.8 & 85.4 & & 83.5 & & $1.06(1.02,1.10)$ & $0.99(0.92,1.06)$ \\
\hline $\begin{array}{l}\text { Average }( \pm S D) \text { number of other } \\
\text { medications, } 2004\end{array}$ & $\begin{array}{c}9.0 \pm 6.5 \\
\text { (Median: 8; IQR: } \\
4-12 \text { ) }\end{array}$ & $\begin{array}{c}8.4 \pm 6.9 \\
\text { (Median: 7; IQR: } \\
\text { 3-12) }\end{array}$ & $<0.01$ & $\begin{array}{c}9.3 \pm 7.5 \\
\text { (Median: 8; IQR: } \\
\text { 3-13) }\end{array}$ & $<0.01$ & $1.02(1.01,1.02)$ & $1.04(1.04,1.05)$ \\
\hline Average ( \pm SD) MPR, 2004 & $\begin{array}{c}93.8 \pm 15.5 \\
\text { (Median: 98.6; } \\
\text { IQR: 88.5-98.8) }\end{array}$ & $\begin{array}{c}91.2 \pm 18.0 \\
\text { (Median: 90.4; } \\
\text { IQR: 80.8-98.8) }\end{array}$ & $<0.01$ & $\begin{array}{c}87.9 \pm 24.3 \\
\text { (Median: 87.6; } \\
\text { IQR: 73.7-98.9) }\end{array}$ & $<0.01$ & $0.99(0.99,0.99)$ & $0.98(0.98,0.98)$ \\
\hline
\end{tabular}

$\mathrm{CARP}=$ coronary artery revascularisation procedure; $\mathrm{Cl}=$ confidence interval; IHD = ischaemic heart disease; IQR = interquartile range; $\mathrm{MPR}=$ medication possession ratio; OR = odds ratio;

$\mathrm{PDC}=$ proportion of days covered; $\mathrm{SD}=$ standard deviation; $\mathrm{NA}=$ not applicable

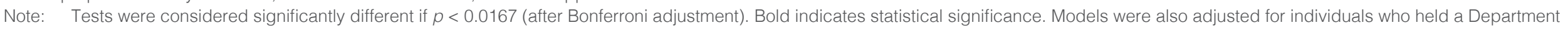
of Veterans' Affairs healthcare card as a binary variable. 


\section{Characteristics associated with ceasing statin} medication in 2005

The overall univariate results (Supplementary

Table 1A, available from: researchonline.nd.edu.au/ med_article/1022/) were similar to the adjusted analysis

(Table 1). Younger adults had higher odds of cessation compared with those aged $>80$ years ( $\leq 40$ years

adjusted OR 2.00; 95\% Cl 1.68, 2.36). Individuals living in inner regional areas were less likely to cease statin use compared with those living in major cities (adjusted OR 0.89; 95\% Cl 0.83, 0.96). However, individuals living in very remote areas had $40 \%$ increased odds of ceasing statin use compared with those living in major cities. Individuals with no previous IHD or CARP history had increased odds of ceasing compared with those with a prior history of IHD or CARP (for IHD: adjusted OR 1.17; 95\% Cl 1.04, 1.31; for CARP: adjusted OR 1.39; 95\% Cl $1.17,1.65)$. New statin users had three times the odds of cessation compared with individuals with previous statin usage. General beneficiaries had $41 \%$ increased odds of ceasing statin use compared with concessional beneficiaries. Those not taking other cardiovascular medication in 2004 were more likely to cease statin use (adjusted OR 1.29; 95\% Cl 1.22, 1.37). A 4\% increase in the odds of ceasing was seen for every additional medication dispensed. Higher statin adherence levels in 2004 were significantly associated with individuals being less likely to cease (adjusted OR 0.98; $95 \% \mathrm{Cl}$ $0.98,0.98)$. Sex, socio-economic disadvantage, history of stroke and taking diabetic medication were not significant predictors of cessation.

When stratified by beneficiary status, the general beneficiaries' age was no longer a significant predictor, while it was for concessional beneficiary status. For concessional beneficiaries, residing in a very remote area was a significant predictor for cessation, while general beneficiaries living in an inner regional area were less likely to cease compared to those living in major cities (Supplementary Table 1A, available from: researchonline. nd.edu.au/med_article/1022/).

\section{Characteristics associated with reducing statin medication in 2005}

The overall univariate results (Supplementary

Table 2A, available from: researchonline.nd.edu.au/ med_article/1022/) were similar to the adjusted analysis (Table 1). When compared with the group that continued therapy, the odds of reducing statin use were higher for adults aged $<60$ years compared with adults aged $>80$ years (e.g. 51-60 years adjusted OR 1.13; 95\% Cl $1.07,1.20)$. Greater socio-economic disadvantage was associated with a reduction; the odds of reducing use were $13 \%$ higher for individuals with the most socioeconomic disadvantage compared to those with the least. The impact of remoteness varied when compared to major cities, with individuals living in inner regional areas having $5 \%$ lower odds of reducing, while individuals living in very remote areas were $28 \%$ more likely to reduce statin use.

Individuals who were new statin users had increased odds of reducing use compared with those with a history of statin use (adjusted OR 2.33; 95\% Cl 2.25, 2.42). Individuals with general beneficiary status had a 17\% increase in their odds of reducing statin use compared with those with concessional beneficiary status. For individuals not taking other cardiovascular medication, the odds of reducing increased by 32\% compared with those taking cardiovascular medication. Those not taking diabetes medication in 2004 were more likely to reduce statin use (adjusted OR 1.06; 95\% Cl 1.02, 1.10). A $2 \%$ increase in the odds of reducing was observed for every additional medication dispensed. Higher adherence levels in 2004 were significantly associated with individuals being less likely to reduce use of the medication (adjusted OR 0.99; 95\% Cl 0.99, 0.99). Sex, history of IHD, history of stroke and history of CARP were not significant predictors of reducing statin therapy.

When stratified by beneficiary status, women who were general beneficiaries had increased odds of reducing statin use (adjusted OR 1.06; 95\% Cl 1.01, 1.11) compared with males, but this was not a significant predictor for concessional beneficiaries (Supplementary Table 2A, available from: researchonline.nd.edu.au/med_ article/1022/). For individuals with general beneficiary status, living in inner regional areas was associated with $13 \%$ lower odds of reducing statin use compared with those living in major cities, while concessional beneficiaries living in very remote areas had 56\% increased odds of reducing use compared with those living in major cities.

\section{Comparison with 2004}

Using 2004-2005 data, $83.9 \%$ of statin users continued their medication in 2005, $12.9 \%$ reduced their use by $>20 \%$ and $3.2 \%$ ceased statin use for at least the first 6 months of 2005. In 2003-2004, 86.0\% continued use, $11.6 \%$ reduced use and $2.4 \%$ ceased use.Therefore, the likely attributable fraction from the additional PBS copayment was $0.8 \%$ for those who ceased statin medication, and $1.3 \%$ for those who reduced statin medication.

\section{Discussion}

This study examined individual-level demographic and clinical characteristics of individuals in WA who continued, reduced or ceased their statin medication following the $21 \%$ PBS copayment increase in January 2005. We observed that $16 \%$ of statin users reduced or discontinued medication in 2005 , and $2.1 \%$ of users appeared to reduce or discontinue medication due to the copayment increase. Being younger in age and a new statin user were the two strongest predictors of ceasing 
or reducing statin medication. Greater socio-economic disadvantage, living in very remote areas, no previous IHD, no previous CARP, general beneficiary status, not taking other cardiovascular or diabetic medications, total medication use, and lower MPR in 2004 were also associated with either ceasing or reducing use of statin medication.

Every year, people reduce or cease statin medication, and previous research has identified many factors that influence individuals' decisions to discontinue statin therapy and adherence levels to therapy. The most common reason for discontinuation or reduction in statin therapy is experiencing statin-associated symptoms. ${ }^{18}$ Other factors include low health literacy, low social status, existence of comorbid conditions, and polypharmacy. ${ }^{19}$ An Australian study demonstrated that being older, obese, having less than excellent self-rated health or prior history of heart disease resulted in greater statin adherence. Risk factors for nonadherence included speaking languages other than English at home, being employed, smoking and reporting substantial psychological distress. ${ }^{20}$

The findings from our study support the existing literature both in Australia and overseas showing that a copayment increase is associated with more individuals ceasing or reducing their medication, and that certain subgroups are more likely to be affected by a significant increase in the copayment for medication. 1,3,21-24 An Australian study, using selfreporting by 770 participants, found that the groups most likely to reduce their medication use due to cost were young adults, low-income earners, the chronically ill, those with high out-of-pocket costs, Aboriginal and Torres Strait Islander people, and individuals who did not feel involved in decisions about their treatment. ${ }^{21}$ More specifically, the low-income general beneficiaries group has been classified as the 'working poor', who, despite having a salary, struggle to meet out-of-pocket medical expenses. ${ }^{25}$ Previous research on the 2005 January PBS copayment increase using aggregated data demonstrated that the reduction in use of statin medication was not specific to remote and disadvantaged areas, and that the largest impact was seen for lowincome patients. ${ }^{22,26}$

This study adds to the existing literature by providing policy makers and clinicians with additional information about the impacts of large medication copayment increases on specific subgroups that may be at a higher risk of being affected.

\section{Strengths and limitations}

The majority of previous Australian studies specifically on medication copayments have been conducted using aggregated data, whereas our study used populationbased individual-level data. This enabled an in-depth look at specific clinical and demographic characteristics and their associations with changes in statin use. The use of routinely collected data eliminates recall bias, loss to follow-up (as it includes whole-of-population capture) and low response as issues for the analysis. This study was conducted using data from WA, which is representative of other states and territories in Australia; hence, the study's findings are likely to be generalisable to Australia as a whole. ${ }^{27}$

This study was restricted to statin medication and did not analyse whether some individuals may have ceased or reduced medication because they switched to another lipid-lowering therapy. However, non-statin lipid-lowering medication represented only $3 \%$ of all lipid-lowering medications dispensed in 2004.

This study reviewed PBS data between 2002 and 2005, during which time data were not collected on medications costing less than the patient general beneficiary copayment or those that were dispensed privately. This included two of the 14 subsidised statin medications (fluvastatin $20 \mathrm{mg}$ and simvastatin $5 \mathrm{mg}$ ). The same restrictions would also have affected PBS data regarding the number of cardiovascular and diabetes medications, and the number of other medications for general beneficiaries, by underestimating these variables. Additionally, PBS data contain no information on dosage; hence, adherence measures are an estimation based on an individual's dispensing history.

Hospital admissions for IHD and stroke may be an underrepresentation because the look-back period was from 2000, and hospital admissions outside WA or events that occurred outside the hospital are not included.

\section{Conclusion}

This study is the first to examine the effects of the January 2005 increase in PBS medication copayments on statin medication use using individual-level administrative data. Compared with 2004, an additional $2.1 \%$ of statin users reduced or discontinued medication use in 2005. Changes in the cessation or reduction in use of statins, irrespective of the copayment, need attention. Certain subgroups were more affected, including individuals with general beneficiary status, and younger and healthier individuals. These subgroups are not always recognised as high-risk groups for medication cessation or reduction, and need to be identified and considered by clinicians and policy makers.

\section{Acknowledgements}

This project was supported by a National Health and Medical Research Council Project Grant (\#456408). We thank the WA Department of Health (Hospital Morbidity Data Collection and Registrar General) and the Australian Department of Health for providing the cross-jurisdictional linked data used in this study. We also thank the Western Australia Data Linkage Branch for extraction of the local administrative data. 


\section{Peer review and provenance}

Externally peer reviewed, not commissioned.

\section{Competing interests}

GW has been a board member with Amgen and Regeneron, has done consultancy work for Amgen and Sanofi and received grants from Amgen, Regeneron and Sanofi. He has received payment for lectures for Kowa, Amgen and Sanofi.

\section{Author contributions}

KS wrote the first draft and conducted the analysis with assistance of DP, FS and MB. All authors contributed to interpreting the results and commenting on the manuscript drafts.

\section{References}

1. Schoen C, Osborn R, Squires D, Doty MM, Pierson R, Applebaum S. How health insurance design affects access to care and costs, by income, in eleven countries. Health Aff. 2010;29(12):2323-34.

2. Australian Government Department of Health. PBS: The Pharmaceutical Benefits Scheme. Canberra: Commonwealth of Australia; 2019. About the PBS [cited 2017 Dec 1]; [about 3 screens]. Available from: www.pbs.gov.au/info/about-the-pbs

3. Hynd A, Roughead EE, Preen DB, Glover J, Bulsara MK, Semmens J. The impact of co-payment increases on dispensings of government-subsidised medicines in Australia. Pharmacoepidemiol Drug Saf. 2008;17(11):1091-9.

4. McManus P, Donnelly N, Henry D, Hall W, Primrose J, Lindner J. Prescription drug utilization following patient co-payment changes in Australia. Pharmacoepidemiol Drug Saf. 1996;5(6):385-92.

5. Tamblyn R, Laprise R, Hanley JA, Abrahamowicz M, Scott S, Mayo N, et al. Adverse events associated with prescription drug cost-sharing among poor and elderly persons. JAMA. 2001;285(4):421-9.

6. Hynd A, Roughead EE, Preen DB, Glover J, Bulsara M, Semmens J. Increased patient co-payments and changes in PBS-subsidised prescription medicines dispensed in Western Australia. Aust N Z J Public Health. 2009;33(3):246-52.

7. Schaffer AL, Buckley NA, Dobbins TA, Banks E, Pearson S-A. The crux of the matter: did the ABC's Catalyst program change statin use in Australia? Med $\mathrm{J}$ Aust. 2015;202(11):591-5.
8. Australian Government Department of Health. PBS: The Pharmaceutical Benefits Scheme. Canberra: Commonwealth of Australia; 2017. Supplying medicines - what pharmacists need to know [cited 2017 Dec 1]; [about 4 screens]. Available from: www.pbs.gov.au/ info/healthpro/explanatory-notes/section1/Section_1_3_ Explanatory_Notes

9. Donnelly N, McManus P, Dudley J, Hall W. Impact of increasing the re-supply interval on the seasonality of subsidised prescription use in Australia. Aust N Z J Public Health. 2000;24(6):603-6.

10. Seaman KL, Sanfilippo FM, Roughead EE, Bulsara MK, Kemp-Casey A, Bulsara C, et al. Impact of consumer copayments for subsidised medicines on health services use and outcomes: a protocol using linked administrative data from Western Australia. BMJ Open 2017;7(6):e013691.

11. Andrade SE, Kahler KH, Frech F, Chan KA. Methods for evaluation of medication adherence and persistence using automated databases. Pharmacoepidemiol Drug Saf. 2006;15(8):565-74.

12. Australian Bureau of Statistics. Census of population and housing: Socio-Economic Indexes for Areas (SEIFA), Australia 2016. Canberra: ABS; 2013 [cited 2017 Dec 1]. Available from: www.abs.gov.au/ausstats/abs@.nsf/ $\mathrm{mf} / 2033.0 .55 .001 /$

13. Australian Government Department of Health. Accessibility Remoteness Index of Australia (ARIA) Remoteness Area (RA). Canberra: Commonwealth of Australia; 2018 [cited 2019 Mar 12]; [about 3 screens]. Available from: www.health.gov.au/internet/publications/ publishing.nsf/Content/ARIA-Review-Report-2011 ARIAReview-Report-2011-2 ARIA-Review-Report-2011-2-2-3

14. WHO Collaborating Centre for Dug Statistics Methodology. Oslo, Norway: WHO Collaborating Centre for Drug Statistics Methodology; 2013. Cardiovascular system [cited 2017 Sep 13]; [about 2 screens]. Available from: www.whocc.no/atc_ddd_index/?code=C\&showdes cription=yes

15. WHO Collaborating Centre for Dug Statistics Methodology. Oslo, Norway: WHO Collaborating Centre for Drug Statistics Methodology; 2016. A10 drugs used in diabetes [cited 2017 Sep 13]; [about 1 screen]. Available from: www.whocc.no/atc_ddd_index/?code=A10

16. Australian Consortium for Classification Development. The international statistical classification of diseases and related health problems, tenth revision, Australian modification (ICD-10-AM/ACHI/ACS): ninth edition. Sydney: Independent Hospital Pricing Authority; 2015 [cited 2019 Apr 29]. Available from: www.accd.net.au/ Icd10.aspx?page=2 
17. Australian Consortium for Classification Development. The international statistical classification of diseases and related health problems, tenth revision, Australian modification (ICD-10-AM/ACHI/ACS): tenth edition. Sydney: Independent Hospital Pricing Authority; 2017 [cited 2019 Apr 29]. Available from: www.accd.net.au/ Icd10.aspx?page=3

18. Cohen JD, Brinton EA, Ito MK, Jacobson TA. Understanding statin use in America and gaps in patient education (USAGE): an internet-based survey of 10,138 current and former statin users. J Clin Lipidol. 2012;6(3):208-15.

19. Chowdhury R, Khan H, Heydon E, Shroufi A, Fahimi S, Moore C, et al. Adherence to cardiovascular therapy: a meta-analysis of prevalence and clinical consequences. Eur Heart J. 2013;34(38):2940-8.

20. Warren JR, Falster MO, Fox D, Jorm L. Factors influencing adherence in long-term use of statins. Pharmacoepidemiol Drug Saf. 2013;22(12):1298-307.

21. Kemp A, Roughead E, Preen D, Glover J, Semmens J. Determinants of self-reported medicine underuse due to cost: a comparison of seven countries. J Health Serv Res Policy. 2010;5(2):106-14.
22. Kemp A, Glover J, Preen DB, Bulsara M, Semmens J, Roughead EE. From the city to the bush: increases in patient co-payments for medicines have impacted on medicine use across Australia. Aust Health Rev. 2013;37(1):4-10.

23. Menzies Centre for Health Policy and Nous Group. Survey of attitudes towards the Australian health system part 2: financial stress and health. Sydney: Menzies Centre for Health Policy; 2009 [cited 7 Mar 2017]. Available from: ses.library.usyd.edu.au/bitstream/2123/19 909/2/2008surveyfinancialsummary.pdf

24. Kemp A. Consumer co-payments for medicines: impact on use and the role of the pharmacist. Australian Pharmacist. 2010;29(9):747-8.

25. Payne A. Working poor in Australia: an analysis of poverty among families in which a member is employed. Family Matters. 2009;81:15-24.

26. Kemp A, Preen D, Sanfilippo F, Glover J, Semmens J, Roughead E. Evaluating pharmaceutical policy impact using interrupted time series analysis: an Australian case study. Int Public Health J. 2011;3(2):229-41.

27. Clark A, Preen DB, Ng JQ, Semmens JB, Holman D. Is Western Australia representative of other Australian States and Territories in terms of key socio-demographic and health economic indicators? Aust Health Rev. 2010; 34(2):210-15.

\section{Copyright: (c)}

(C) 2019 Seaman et al. This article is licensed under the Creative Commons Attribution-NonCommercial-ShareAlike 4.0 International Licence, which allows others to redistribute, adapt and share this work non-commercially provided they attribute the work and any adapted version of it is distributed under the same Creative Commons licence terms. See: www.creativecommons.org/licenses/by-nc-sa/4.0/ 